\section{Prognostic factors for chronic kidney disease and end-stage renal disease in patients with lupus nephritis: A retrospective cohort study}

\author{
Fernanda Nogueira Holanda Ferreira Braga ${ }^{1 *}$, Marta Maria \\ das Chagas Medeiros ${ }^{1}$, Antônio Brazil Viana Jr. ${ }^{1}$, Levi Coelho \\ Maia Barros ${ }^{2}$, Marcelo Ximenes Pontes², Matheus Eugênio \\ de Sousa Lima ${ }^{2}$, Allyson Wosley de Sousa Lima ${ }^{2}$ and Paula \\ Frassinetti Castelo Branco Camurça Fernandes ${ }^{1}$
}

\author{
${ }^{1}$ Universidade Federal do Ceará, Brazil \\ Universidade Estadual do Ceará, Brazil
}

\section{Abstract}

Background: Lupus Nephritis (LN) occurs in approximately half of all patients with Systemic Lupus Erythematosus (SLE) and it is the most common cause of morbidity and mortality in patients with SLE. Factors associated with poor renal outcome vary among studies, and researches coming from Brazil are scarce.

Objectives: To identify the prognostic factors associated to the development of Chronic Kidney Disease (CKD) and End Stage Renal Disease (ESRD) in LN patients followed in a tertiary hospital.

Design and Settings: We conducted a retrospective cohort study set in a tertiary hospital in Fortaleza, Ceará, Brazil. Methods: We compiled a total of 214 LN patients diagnosed between 1983 and 2015. Data was collected from medical records and further analyzed using logistic regression.

Results: LN prevalence was $53.9 \%$. The cohort had a mean follow-up of 11.2 years (SD \pm 7.2 years). At the end of follow-up, 93 of 197 patients (47.2\%) had CKD, and 49 of $191(25.6 \%)$ were on regular dialysis. The main factors associated for developing CKD after logistic regression analysis were the following predictors: hypertension (HR 2.80; 95\% Cl 1.30-6.01; $p=0.008$ ), time between diagnosis of SLE and diagnosis of LN (HR 0.98; 95\% Cl 0.97-0.99; $p=0.009)$ and discontinuation of medications (HR 2.41; 95\% Cl 1.08-5.37; $p=0.03$ ).

Conclusion: Hypertension, discontinuation of medications, and time between diagnosis of SLE and diagnosis of LN are independent variables associated with the development of CKD and ESDR in our study.

\section{More Information}

*Address for Correspondence:

Fernanda Nogueira Holanda Ferreira Braga,

Rua Silva Paulet 2051, apt 1301, 60120-021, Fortaleza, Ceará, Brazil, Tel: +55 85 999441139;

Email: fnhfb@yahoo.com.br

Submitted: March 25, 2021

Approved: April 26, 2021

Published: April 27, 2021

How to cite this article: Braga FNHF, das Chagas Medeiros MM, Viana AB, Jr., Barros LCM, Pontes MX, et al. Prognostic factors for chronic kidney disease and end-stage renal disease in patients with lupus nephritis: A retrospective cohort study. J Clini Nephrol. 2021; 5: 034-041.

DOI: 10.29328/journal.jcn.1001071

Copyright: (c) 2021 Braga FNHF, et al. This is an open access article distributed under the Creative Commons Attribution License, which permits unrestricted use, distribution, and reproduction in any medium, provided the original work is properly cited.

Keywords: Lupus; Lupus nephritis; Prognostic features; Epidemiology

Mesh terms: Nephritis, Lupus; End Stage Renal Disease; Chronic Kidney Disease; Risk Factor

Check for updates

OPEN ACCESS

\section{Introduction}

Lupus nephritis (LN) occurs in approximately half of all patients with systemic lupus erythematosus (SLE), and its frequency ranges from $12 \%$ to $75 \%$, depending on the population studied and the diagnostic criteria used [1-6]. Lupus nephritis is the most common cause of morbidity and mortality in patients with SLE [7] and the incidence and severity of this manifestation are increased in patients with African, Hispanic and Asian ancestry [1]. Multiple genetic, socioeconomic, environmental, and clinical factors may account for this phenomenon. Lupus nephritis is the most prevalent etiology of secondary glomerular disease leading to chronic kidney disease (CKD) and end-stage renal disease (ESRD) [8]. The development of chronic kidney disease is a global public health problem, and also is associated with cardiovascular disease [9-11].

Although the renal survival rate has improved with the implementation of current immunosuppressive regimens, 
nearly $10 \%-20 \%$ of patients with LN still progress do ESRD [12]. Factors associated with poor renal outcomes vary among studies, and most of these studies come from Europe, the USA and Asia, with scarce reports from Brazil. The identification of epidemiologic and clinical factors associated with CKD and ESRD in different populations will improve our understanding of $\mathrm{LN}$, facilitate the diagnosis and management, and improve the prognosis.

The aim of the present retrospective study was to identify the demographic, clinical, and histological factors associated with the developing of CKD and ESRD in a cohort of LN patients (with LN) of a single center in Northeastern Brazil.

\section{Patients and methods}

\section{Patients}

The initial sample consisted of 830 SLE patients previously or currently followed at the Hospital Universitário Walter Cantídio (HUWC/Universidade Federal do Ceará) in Fortaleza, Brazil, identified between 2011 and 2015 through active search of the records (including names and chart numbers) of outpatient services and wards, pharmacy and hospital databases, and research notes from earlier studies on SLE patients at HUWC. Chart numbers were arranged in increasing order (reflecting the order of hospital admission) and divided into groups of 50 patients, from which half were randomly selected for retrospective in-depth review. The decision to review approximately half the records $(n=414)$ was justified by logistic limitations. To be included in the sample, patients should had been diagnosed with SLE according to the criteria of the American College of Rheumatology (1982) [13], had no associated autoimmune disorder (rheumatoid arthritis, polymyositis, dermatopolymyositis, systemic sclerosis), and have been followed by the HUWC for at least one year or until their death. Records which did not meet the criteria for analysis were replaced by records drawn at random from the same group. The sample included patients from four different services at HUWC (rheumatology, nephrology, pediatrics and internal medicine). The prevalence of lupus nephritis in this sample cohort of 414 patients was 53.9\% (233 patients). Nineteen patients were excluded because of incomplete data (15) or overlap with systemic sclerosis (3). We retrospectively studied all 214 patients with LN defined according to the presence, of two consecutive lab tests, of one of the following alterations: red blood cell casts or hemegranular casts, or white blood cell casts, or hematuria, or pyuria, or proteinuria ( $>500 \mathrm{mg} / 24$ hours or $\geq 3+$ on dipstick), in the absence of other causes, and/or an abnormal renal biopsy showing any classes of the World Health Organization/the International Society of Nephrology pathologic classification [14].

HUWC is a public university hospital and tertiary-level referral facility. Most users originated from socioeconomically underprivileged communities in Fortaleza (the state capital), the hinterland of Ceará, and other states in Northeastern Brazil.

\section{Study parameters}

Demographic data (gender, race, age at diagnosis of SLE and LN), clinical data (SLE manifestations at any stage, time between LN diagnosis and first treatment done for LN, follow-up time [from diagnosis of LN to the development of CKD, ESRD, last evaluation and/or death], induction and maintenance immunosuppressive treatment (medication administered in induction and maintenance phases), reasons of stopping medications [inefficiency, lack of adhesion, adverse events, medication unavailability], presence of arterial hypertension during the follow-up [systolic blood pressure $\geq 140 \mathrm{mmHg}$ and/or diastolic blood pressure $\geq$ $90 \mathrm{mmHg}$ or if on treatment with anti-hypertensive drugs], complete and partial renal remission after induction treatment and in the end of the follow-up, number of renal flares, time in remission), laboratory data at onset of LN, and after 3, 6 and 12 months (serum creatinine, estimated glomerular filtration rate [eGFR] CKD-Epi, and $24 \mathrm{~h}$ urinary protein excretion) and immunological data in any time of the disease (antinuclear antibodies, IgG/IgM anticardiolipin antibodies, lupus anticoagulant, anti-dsDNA and anti-Sm antibodies) were retrieved from the medical records using a standardized form. Complete remission (CR) was defined as proteinuria $<500 \mathrm{mg} / 24$ hours, normal renal function, and inactive urine sediment. Partial remission (PR) was defined as proteinuria between $500 \mathrm{mg}-1000 \mathrm{mg} / 24$ hours, normal renal function, and inactive urine sediment. Renal flare was defined by any presence of cast, proteinuria $>500 \mathrm{mg} / 24$ hours and/or hematuria after CR, and without other cause.

Regarding patients who underwent renal biopsy in any time of the follow-up, only data from the first biopsy were considered for the study, even though some patients had more than one biopsy.

Chronic kidney disease was defined according to the Kidney Disease: Improving Global Outcome definition (estimated glomerular filtration rate $<60 \mathrm{ml} / \mathrm{min} / 1.73 \mathrm{~m}^{2}$ of body surface area for 3 months or more) [15]. CKD is classified in five stages. However, for comparison purposes, we used the cutoff point of $<60 \mathrm{ml} / \mathrm{min}$ (correspondent to stage II CKD)

End-stage renal disease was defined as the need for permanent hemodialysis or peritoneal dialysis.

The study protocol was approved by the HUWC Research Ethics Committee and filed under number 90562917.1.3001.5045.

\section{Statistical analysis}

Statistical analysis was performed using the RedCap program. Values are expressed as means \pm standard deviation or median (IQR) for continuous variables and percentages for categorical variables. A $p$ value $<0.05$ was considered to indicate statistical significance. Comparisons of continuous variables were based on the t test or Mann-Whitney test. 
The chi-square and Fisher exact test were used to compare categorical variables. A multivariate logistic regression analysis was applied using variables that were statistically significant in univariate analysis, and when there was less than $20 \%$ of missing data for each variable.

\section{Results}

A total of $214 \mathrm{LN}$ patients were studied. Most of the patients were female (90.6\%), and non-white (80\%), with a mean age at diagnosis of SLE of $25.8 \pm 8.9$ years and a mean age at diagnosis of LN of $27.3 \pm 9.2$ years (Table 1 ). Clinical manifestations were mostly musculoskeletal (82.2\%), dermatological (73.8\%), serosites (46.7\%), and leucolymphopenia (41.5\%). The ANA test was positive in $95 \%$,

Table 1: Demographics and disease related features in 214 patients with lupus nephritis.

\begin{tabular}{|c|c|}
\hline Variable & \\
\hline Female; $n(\%)$ & $194(90.6)$ \\
\hline $\begin{array}{l}\text { Level of schooling; } n(\%) \\
\text { Basic literacy } \\
\text { Elementary school } \\
\text { High school } \\
\text { College or higher } \\
\text { Unknown information }\end{array}$ & $\begin{array}{c}23(10.7) \\
33(15.4) \\
58(27.1) \\
12(5.6) \\
88(41.2)\end{array}$ \\
\hline $\begin{array}{l}\text { Racial distribution; } n(\%) \\
\text { White } \\
\text { Non-white } \\
\text { Unknown information }\end{array}$ & $\begin{array}{c}31(14.5) \\
115(53.7) \\
57(26.7)\end{array}$ \\
\hline Age at diagnosis of SLE; mean \pm SD & $25.8 \pm 8.9$ \\
\hline Age at diagnosis of $L N$; mean $\pm S D$ & $27.3 \pm 9.2$ \\
\hline Time between SLE and LN diagnosis; median (IQR), months & $0(0-19.5)$ \\
\hline Serum creatinine at diagnosis of $\mathrm{LN}$; mean $\pm \mathrm{SD}, \mathrm{mg} / \mathrm{dL}$ & $1.45 \pm 1.28$ \\
\hline Proteinuria 24 hours at diagnosis of $\mathrm{LN}$; mean $\pm \mathrm{SD}$, $\mathrm{mg}$ & $2903.9 \pm 3051.3$ \\
\hline Serum albumin at diagnosis of $\mathrm{LN}$; mean $\pm \mathrm{SD}, \mathrm{g} / \mathrm{dL}$ & $2.51 \pm 0.78$ \\
\hline eGFR; mean $\pm \mathrm{SD}\left(\mathrm{ml} / \mathrm{min} / 1.73 \mathrm{~m}^{2}\right)$ & $77.5 \pm 40.9$ \\
\hline Low levels of C3 and/or C4; \% ( $n$ /total) & $78.2(100 / 128)$ \\
\hline Anti dsDNA; \% ( $n$ /total) & $58(47 / 81)$ \\
\hline Dialysis at diagnosis of LN; \% ( $n$ /total) & $6.2(12 / 192)$ \\
\hline $\begin{array}{l}\text { Histological classification of LN (122 patients): } \\
\qquad \text { III } \%(n \text { /total) } \\
\text { IV; } \%(n \text { /total }) \\
\text { V; } \%(n \text { /total }) \\
\text { Activity index; mean } \pm \text { SD } \\
\text { Chronicity index; mean } \pm \text { SD }\end{array}$ & $\begin{array}{c}21.6(22 / 102) \\
53.9(55 / 102 \\
13.7(14 / 102) \\
7.6 \pm 4.4 \\
1.1 \pm 1.9\end{array}$ \\
\hline $\begin{array}{l}\text { First treatment to induction of remission; \% (n/total) } \\
\text { Intravenous cyclophosphamide } \\
\text { Azathioprine } \\
\text { Mycophenolate mofetil }\end{array}$ & $\begin{array}{l}55.6(108 / 194) \\
33.5(65 / 194) \\
10.8(21 / 194)\end{array}$ \\
\hline $\begin{array}{c}\text { Time between NL diagnosis and treatment; median (IQR), } \\
\text { months }\end{array}$ & $0(0-1)$ \\
\hline $\begin{array}{l}\text { Complete remission after first induction of remission treatment; } \\
\% \text { (n/total) } \\
\text { Partial remission after first induction of remission treatment; } \\
\%(\mathrm{n} / \text { total) }\end{array}$ & $\begin{array}{c}18.2(39 / 214) \\
3.3(7 / 214)\end{array}$ \\
\hline Time to achieve CR or PR; median (IQR), months & $12(6-28)$ \\
\hline Renal flare; \% ( $n$ /total) & $38.9(81 / 208)$ \\
\hline Follow-up duration; mean $\pm \mathrm{SD}$, years/ median (IQR), years & $\begin{array}{c}11.2 \pm 7.2 / 10 \\
(0-32)\end{array}$ \\
\hline Chronic kidney disease; \% ( $n$ /total) & $47.2(93 / 197)$ \\
\hline Time to develop CKD; median (IQR), months & $60(12-141)$ \\
\hline End-stage renal disease: \% (n/total) & $25.6(49 / 191)$ \\
\hline Time to develop ESRD; median (IQR), months & $72(20-150)$ \\
\hline
\end{tabular}

SLE: Systemic Lupus Erythematosus; LN: Lupus Nephritis; eGFR: estimated Glomerular Filtration Rate; CR: Complete Renal Remission; PR: Partial Renal Remission; IQR: Interquartile Range; CKD: Chronic Kidney Disease; ESRD: End-Stage Renal Disease. with autoantibodies in the following order of frequency: antidsDNA (58\%), anti-Sm (38.9\%), lupus anticoagulant (26.4\%) and anticardiolipin (15.5\%). The mean serum creatinine on LN diagnosis was $1.45 \pm 1.28 \mathrm{mg} / \mathrm{dL}$, urinary protein were $2903.9 \pm 3051.3 \mathrm{mg} / 24$ hours, the mean serum albumin was $2.51 \pm 0.78 \mathrm{~g} / \mathrm{dL}$, and the eGFR-CKD-EPI was $77.5 \pm 40.9 \mathrm{ml} /$ $\min / 1.73 \mathrm{~m}^{2}$. Among the 214 patients, 102 patients (47.6\%) underwent renal biopsy and the most prevalent histological lupus nephritis classes were class IV (53.9\%) and class III (21.6\%). Only 14 patients (13.7\%) showed class V. The renal activity index was $7.6 \pm 4.4$ and the renal chronicity index was $1.1 \pm 1.9$. Thrombotic microangiopathy was described in only one patient who presented antiphospholipid antibody syndrome. Of the 214 patients, one hundred and ninetyfour had information recorded on charts about the first immunosuppressive drug to induce remission of LN. The most used was IV cyclophosphamide (55.6\%), azathioprine (AZA) (33.5\%) and mycophenolate mofetil (MMF) (10.8\%). After 6 months using the first induction treatment for remission, only 39 (18.2\%) and 7 (3.3\%) patients reached CR and PR, respectively. The median time to reach remission was 12 months (IQR 6-28 months). The total number of patients who had renal flares during follow-up was 81 (38.9\%). The cohort had a mean follow-up of 11.2 years (SD \pm 7.2 years). At the end of follow-up, 93 of 197 patients (47.2\%) had CKD, and 49 of 191 (25.6\%) were on regular dialysis (Table 1). During the follow-up, methylprednisolone pulse (0.5-1g/day for 3 days) was used for induction of remission 125 times in 214 patients (58.9\%), IV cyclophosphamide was used 152 times (55.6\%), AZA was used 133 times for induction of remission (33.5\%) and MMF in $51.9 \%$ of the time. The reasons for discontinuing the medications in any time of the treatment are presented in the table 2.

Univariate analyses were performed to identify the predictors for the development of CKD and ESRD, as show in table 3. With regard to $\mathrm{CKD}$, thrombocytopenia and hypertension were more frequent in patients who developed CKD. Closer time between LN and SLE diagnosis (11.5 \pm 27.6 vs. $27.3 \pm 49.1$ months; $p=0.01)$, longer time to initiate treatment after LN diagnosis ( $2.6 \pm 5.6$ vs. $1.0 \pm 4.2$ months; $p=0.004)$, and dialysis onset at LN diagnosis (10\% vs. 2.9\%; $p=0.04$ ) were more associated with CKD. Sustained remission for more than 5 years was more frequent in nonCKD patients (74.4\% vs. 25.6\%; $p=0.05)$. In terms of nephritis laboratory findings, patients with CKD at the time of onset of LN had higher creatinine levels $(1.63 \pm 1.26$ vs. $1.21 \pm 0.90$ $\mathrm{mg} / \mathrm{dL} ; p=0.005)$, lower eGFR (70.4 \pm 40.0 vs. $84.8 \pm 39.2$; $p=0.016$ ), and higher 24 hours proteinuria (3507.4 \pm 3606.6 vs. $2595.5 \pm 2605.9 \mathrm{mg} ; p=0.048$ ). Creatinine, eGFR and 24 hours proteinuria at 6 and 12 months were also associated with CKD.

With regard to ESRD, various factors appeared to be risk factors, including younger age at diagnosis of LN (24.8 \pm 8.2 vs. $28.4 \pm 9.6$ years; $p=0.03$ ), shorter interval between 
Table 2: Reasons for discontinuing the immunosuppressive drugs in lupus nephritis.

\begin{tabular}{|c|c|c|c|c|}
\hline Reasons to stop; $\boldsymbol{n}(\%)$ & EV Cyclophosphamide $\left(n=145^{*}\right)$ & Mycophenolate mofetil $\left(n=105^{\star}\right)$ & Azathioprine $\left(n=127^{*}\right)$ & Rituximab $\left(n=7^{*}\right)$ \\
\hline Inefficiency & $36(24.8)$ & $22(20.9)$ & $59(46.4)$ & $2(28.6)$ \\
\hline Nonadherence & $28(19.3)$ & $15(14.3)$ & $16(12.6)$ & 0 \\
\hline Adverse event & $26(17.9)$ & $22(20.9)$ & $23(18.1)$ & $3(42.8)$ \\
\hline Lack of the drug & $0(0)$ & $14(13.3)$ & $4(3.1)$ & 0 \\
\hline
\end{tabular}

Table 3: Clinical predictors of poor renal outcome in patients with lupus nephritis.

\begin{tabular}{|c|c|c|c|c|c|c|}
\hline Variable & $\begin{array}{l}\text { With CKD } \\
(n=93)\end{array}$ & $\begin{array}{l}\text { Without CKD } \\
\qquad(n=104)\end{array}$ & $p$ & $\begin{array}{l}\text { With ESRD } \\
(n=49)\end{array}$ & $\begin{array}{l}\text { Without ESRD } \\
\qquad(n=142)\end{array}$ & p \\
\hline $\begin{array}{l}\text { Sex; \% } \\
\text { Female } \\
\text { Male }\end{array}$ & $\begin{array}{l}46.4 \\
55.6\end{array}$ & $\begin{array}{l}53.6 \\
44.4\end{array}$ & 0.45 & $\begin{array}{l}26.0 \\
22.2\end{array}$ & $\begin{array}{l}74.0 \\
77.8\end{array}$ & 0.99 \\
\hline Age at diagnosis of $L N$; mean $\pm S D$, year & $26.6 \pm 9.4$ & $28.0 \pm 9.1$ & 0.22 & $24.8 \pm 8.2$ & $28.4 \pm 9.6$ & 0.03 \\
\hline Thrombocytopenia; \% & 58.5 & 41.5 & 0.05 & 33.3 & 66.7 & 0.14 \\
\hline $\begin{array}{l}\text { Hypertension; \% } \\
\text { Yes } \\
\text { No }\end{array}$ & $\begin{array}{l}55.6 \\
32.4\end{array}$ & $\begin{array}{l}44.4 \\
67.6\end{array}$ & 0.002 & $\begin{array}{l}26.8 \\
23.5\end{array}$ & $\begin{array}{l}73.2 \\
76.5\end{array}$ & 0.61 \\
\hline $\begin{array}{l}\text { Time between diagnosis of SLE and diagnosis of } L N \text {; } \\
\text { mean } \pm \text { SD/ median (IQR), months }\end{array}$ & $\begin{array}{c}11.5 \pm 27.6 \\
0(0-6)\end{array}$ & $\begin{array}{l}27.3 \pm 49.1 \\
1(0-36)\end{array}$ & 0.01 & $\begin{array}{c}6.6 \pm 20.3 \\
0(0-2)\end{array}$ & $\begin{array}{c}24.5 \pm 45.6 \\
0(0-34.5)\end{array}$ & 0.02 \\
\hline $\begin{array}{l}\text { Time between diagnosis of } \mathrm{LN} \text { and initiation of } \\
\text { treatment; } \\
\text { mean } \pm \mathrm{SD} / \text { median (IQR), months }\end{array}$ & $\begin{array}{l}2.6 \pm 5.6 \\
0(0-2)\end{array}$ & $\begin{array}{l}1.0 \pm 4.2 \\
0(0-0.6)\end{array}$ & 0.004 & $\begin{array}{l}2.4 \pm 5.4 \\
0(0-1)\end{array}$ & $\begin{array}{c}1.6 \pm 4.9 \\
0(0-1)\end{array}$ & 0.49 \\
\hline $\begin{array}{c}\text { Chronicity index; } \\
\text { mean } \pm \mathrm{SD} / \text { median (IQR) }\end{array}$ & $\begin{array}{l}1.7 \pm 2.3 \\
1(0-2)\end{array}$ & $\begin{array}{l}0.6 \pm 1.1 \\
0(0-1)\end{array}$ & 0.20 & $\begin{array}{l}2.2 \pm 2.8 \\
2(0-3)\end{array}$ & $\begin{array}{c}0.7 \pm 1.1 \\
0(0-2)\end{array}$ & 0.05 \\
\hline $\begin{array}{c}\text { Dialysis at LN diagnosis; \% } \\
\text { Yes } \\
\text { No }\end{array}$ & $\begin{array}{l}75.0 \\
45.2\end{array}$ & $\begin{array}{l}25.0 \\
54.8\end{array}$ & 0.04 & $\begin{array}{l}66.6 \\
22.4\end{array}$ & $\begin{array}{l}33.3 \\
77.6\end{array}$ & 0.001 \\
\hline Partial or complete remission; $n(\%)$ & $14(32.5)$ & $29(67.5)$ & 0.06 & $5(11.6)$ & $38(88.4)$ & 0.04 \\
\hline Number of relapses; mean \pm SD & $1.6 \pm 1.3$ & $1.4 \pm 0.7$ & 0.61 & $2.0 \pm 1.7$ & $1.3 \pm 0.6$ & 0.05 \\
\hline Sustained remission > 5 years; $\%$ & 25.6 & 74.4 & 0.05 & 5.2 & 94.8 & 0.03 \\
\hline \multicolumn{7}{|l|}{ Nonadherence (EV cyclophosphamide); \% } \\
\hline $\begin{array}{l}\text { Serum creatinine; mean } \pm \mathrm{SD}, \mathrm{mg} / \mathrm{dl} \\
\text { Baseline } \\
\text { At } 6 \text { months } \\
\text { At } 12 \text { months }\end{array}$ & $\begin{array}{l}1.63 \pm 1.26 \\
1.24 \pm 1.00 \\
1.44 \pm 1.56\end{array}$ & $\begin{array}{l}1.21 \pm 0.90 \\
0.79 \pm 0.23 \\
0.73 \pm 0.18\end{array}$ & $\begin{array}{l}0.005 \\
0.0001 \\
0.0001\end{array}$ & $\begin{array}{l}1.89 \pm 1.55 \\
1.14 \pm 0.78 \\
1.85 \pm 2.08\end{array}$ & $\begin{array}{l}1.23 \pm 1.04 \\
0.93 \pm 0.68 \\
0.81 \pm 0.26\end{array}$ & $\begin{array}{c}0.012 \\
0.26 \\
0.07\end{array}$ \\
\hline $\begin{array}{c}\text { Proteinuria } 24 \text { hours; mean } \pm \mathrm{SD} \text {, mg } \\
\text { Baseline } \\
\text { At } 6 \text { months } \\
\text { At } 12 \text { months }\end{array}$ & $\begin{array}{l}3507.4 \pm 3606.6 \\
1792.2 \pm 1736.1 \\
1915.3 \pm 2424.5\end{array}$ & $\begin{array}{c}2595.5 \pm 2605.9 \\
902.0 \pm 920.2 \\
927.8 \pm 1182.9\end{array}$ & $\begin{array}{l}0.048 \\
0.012 \\
0.001\end{array}$ & $\begin{array}{l}3318.4 \pm 3407.6 \\
2076.3 \pm 1912.7 \\
2077.9 \pm 1858.9\end{array}$ & $\begin{array}{l}2958.6 \pm 3100.2 \\
1093.6 \pm 1193.4 \\
1226.4 \pm 1938.3\end{array}$ & $\begin{array}{c}0.33 \\
0.06 \\
0.001\end{array}$ \\
\hline $\begin{array}{c}\text { eGFR; mean } \pm \mathrm{SD}, \mathrm{ml} / \mathrm{min} / 1.73 \mathrm{~m}^{2} \\
\text { Baseline } \\
\text { At } 6 \text { months } \\
\text { At } 12 \text { months }\end{array}$ & $\begin{array}{l}70.4 \pm 40.0 \\
84.2 \pm 36.8 \\
85.3 \pm 39.9\end{array}$ & $\begin{array}{c}84.8 \pm 39.2 \\
105.2 \pm 26.2 \\
110.1 \pm 22.7\end{array}$ & $\begin{array}{l}0.016 \\
0.002 \\
0.001\end{array}$ & $\begin{array}{l}67.3 \pm 42.7 \\
91.2 \pm 35.5 \\
84.8 \pm 46.9\end{array}$ & $\begin{array}{c}82.1 \pm 38.4 \\
98.2 \pm 31.8 \\
103.2 \pm 27.6\end{array}$ & $\begin{array}{l}0.03 \\
0.46 \\
0.18\end{array}$ \\
\hline
\end{tabular}

SLE: Systemic Lupus Erythematosus; LN: Lupus Nephritis; eGFR: estimated Glomerular Filtration Rate; IQR: Interquartile Range; CKD: Chronic Kidney Disease; ESRD: EndStage Renal Disease

Table 4: Multivariable regression analysis of the predictors of chronic kidney disease in patients with lupus nephritis.

\begin{tabular}{|c|c|c|}
\hline \multicolumn{1}{|c|}{ Variables } & HR (95\% CI) & $\boldsymbol{p}$ value \\
\hline Time between diagnosis of SLE and diagnosis of LN & $0.98(0.97-0.99)$ & 0.009 \\
\hline Hypertension & $2.80(1.30-6.01)$ & 0.008 \\
\hline Discontinuation of medications & $2.41(1.08-5.37)$ & 0.03 \\
\hline HR: Hazard Ratio; Cl: Confidence Interval. & \\
\hline
\end{tabular}

diagnosis of SLE and diagnosis of LN $(6.6 \pm 20.3 v s .24 .5 \pm$ 45.6 months; $p=0.02)$, higher chronicity index $(2.2 \pm 2.8$ vs. $0.7 \pm 1.1 ; p=0.05)$, lower remission rate after induction treatment ( $11.6 \%$ vs. $88.4 \% ; p=0.04)$, more flares $(2.0 \pm 1.7$ vs. $1.3 \pm 0.6 ; p=0.05)$, and lower sustained remission $(5.2 \%$ vs. 94.8\%; $p=0.03$ ). In terms of nephritis laboratory findings, patients with ESRD had higher creatinine levels $(1.89 \pm 1.55$ vs. $1.23 \pm 1.04 \mathrm{mg} / \mathrm{dL} ; p=0.012)$ and lower eGFR $(67.3 \pm 42.7$ vs. $82.1 \pm 38.4 ; p=0.03)$ at baseline, and higher levels of 24 hours proteinuria at 12 months $(2077.9 \pm 1858.9$ vs. 1226.4 $\pm 1938.3 \mathrm{mg} ; p=0.001$ ).
After the logistic regression analysis for developing CKD, only the following variables were predictors for CKD: hypertension (HR 2.80; 95\% CI: 1.30-6.01; $p=0.008$ ), time between diagnosis of SLE and diagnosis of LN (HR 0.98; 95\% CI: $0.97-0.99 ; p=0.009$ ) and discontinuation of medications caused by adverse event, inefficiency or non-adherence (HR 2.41; 95\% CI: 1.08-5.37; $p=0.03$ ).

\section{Discussion}

The prognosis of LN depends on many demographic, 
clinical, histological, laboratory, and therapeutic variables. A number of studies have looked for these predictors with most studies coming from Europe, the USA and Asia. Our study is the first cohort study that evaluated prognostic factors in a single-center from Northeast of Brazil.

The two hundred and fourteen patients were followed for a mean time of 11 years. Almost half of patients (47.2\%) developed CKD, and $25.6 \%$ progressed to dialysis. These are one of the highest rates among studies worldwide. It has been reported that approximately 5\% - 30\% of adults patients with LN will progress to ESRD within 10 years after diagnosis [2,12,16-21], and the incidence of LN-associated ESRD has increased from 1.16 cases per million in 1982 to 4.9 cases per million in 2004 in the United States [22,23]. This increase in the incidence of ESRD attributable to LN is a cause for concern, and the identification of risk factors related with the progression of LN to ESRD is very important to change this scenario. Some of these factors are not modifiable, such as ethnicity, age, gender, immunological profile, histological class of nephritis, response to immunosuppressive therapy. There is a greater likelihood of progression to ESRD among African American and Hispanic patients with LN than among Whites [24]. Pediatric patients with LN show progression to ESRD in $18 \%$ - 50\% [25]. Although our study included only adult patients, lower age was associated with ESRD. Male gender was found to be a poor prognostic factor in some studies [26,27], but not in more recent reports [28,29]. High serum creatinine levels, diffuse proliferative nephritis, tubular atrophy, poor response to immunosuppressive therapy have also been reported to be independent risk factors for ESRD progression [12,18,2,29,30]. Otherwise, some other documented risk factors may be modified, such as delay in treatment of LN [31], hypertension [16-19,32], diabetes mellitus [32], lack of access to medical care [33], no use of standardized protocols for treating LN [34], among others.

In our study, some factors may explain the high rate of CKD and ESRD. First, our patients came from a low socioeconomic background of a tertiary care university hospital. In general, these patients have more severe disease, and with a longer disease duration without diagnosis. At the time of LN diagnosis, our patients had a mean creatinine level of $1.45 \mathrm{mg} / \mathrm{dL}$, a mean 24 hours proteinuria of $2903 \mathrm{mg}$; they had low mean serum albumin $(2.5 \mathrm{mg} / \mathrm{dL})$, and mean eGFR of $77.5 \mathrm{ml} / \mathrm{min} / 1.73 \mathrm{~m}^{2}$; and most of them had anti dsDNA positive (58\%), and hypocomplementenemia (78.2\%). Furthermore, $6.2 \%$ of the patients required hemodialysis at the time of LN diagnosis. Of the 122 patients who underwent renal biopsy, seventy seven (75.5\%) presented with class III and IV. All these factors are associated with more severe disease and poor long-term renal outcome.

Delay in diagnosis and treatment of LN is an important risk factor associated with poor renal outcomes [31]. In our univariate analysis, longer time between diagnosis of LN and initiation of treatment was associated with CKD. Delay of two months on average to begin LN treatment had an impact on outcome. Dialysis, higher serum creatinine, higher $24 \mathrm{~h}$ proteinuria, and lower eGFR at LN diagnosis were also risk factors for CKD in our study. All of these factors are well established as risk factors for poor renal outcomes [16-20, 35-40].

The long-term follow-up of our study ( $>10$ years) has also to be considered to explain the high rates of CKD and ESRD. The longest follow-up study looking for the risk factors for long-term renal outcomes was a cohort of Chinese patients with a mean follow-up period of $93.3 \pm 60.4$ months $(\sim 7.8$ years) [18]. Of the 1814 patients with LN, ESRD developed in $201(11.1 \%)$ patients.

The immunosuppressive medications for $\mathrm{LN}$ in our hospital are supplied by the Secretary of Health of the State of Ceara. However, sometimes the drugs are lacking at the hospital pharmacy, and patients have to stop or switch medications (conversion to other imunossupressive drug), contributing to poorer renal outcomes. Nonadherence is also another reason that may had led patients to progress to CKD and ESRD, and it has proven to be a challenging issue in the treatment of SLE. Rates of nonadherence in patients with SLE vary between $10 \%$ - 50\%, depending in the evaluation methods used [41]. Sometimes severe relapses of LN observed especially in young patients may actually be due to nonadherence rather than to refractory disease [42]. Other reasons for stopping treatment are inefficiency and adverse effect. In our study, the most prevalent reason to stop medication was no therapeutic response which occurred in 46.4\%, 24.8\%, and 20.9\% with AZA, cyclophosphamide, and MMF, respectively. Nonadherence ranged from $12.6 \%$ to $19.3 \%$ among the three main drugs. It is very important consider that in $16.4 \%$ of the time, the reason for discontinuing the immunosuppressive drugs was unavailability in hospital pharmacy, where the MMF is the most lacked drug. The reason for that is the high costs of the drug and the increasing number of patients who needs MMF. As MMF is an effective drug to induce and maintain remission of $\mathrm{LN}$, the discontinuation of treatment may contribute to poorer renal outcomes in our studied population. After multivariable regression analysis of the predictors of CKD, on our patients with LN, the discontinuation of medication for any reason was significantly associated with the development of CKD.

The recommendations for LN management published by Joint European League against Rheumatism and European Renal Association-European Dialysis and Transplant Association (EULAR/ERA-EDTA) propose that a complete renal response or at least a partial response should be achieved preferably within 6 months and no later than 12 months after the induction treatment [43]. Many studies 
have demonstrated that complete or partial remission at 12 months is correlated with better renal outcome $[22,39,44]$. Korbert, et al. reported that the risk for progression to ESRD was 8.2 times greater for patients in whom remission did not occur compared with patients with remission [45]. In our study, lower remission rate was significantly associated with ESRD. In studies of LN, the criteria for response have varied. We used a more rigorous criteria, both for complete and partial remission. Therefore, after 6 months of induction therapy, only $16.4 \%$ of the patients achieved remission, and the median to achieve CR or PR was 12 months in our study. In previous reports, the average duration to remission has ranged from 10 to 16 months after induction therapy $[46,47]$. The durability of remission might be a predictor of renal outcome and survival, as reported by Pakchotanon, et al. [21]. Sustained remission more than 5 years was also associated with better outcome in our study. Renal flares, however, may occur after remission, and they are disadvantageous to the renal function and contribute to morbidity in patients with SLE [44]. In our study, the rate of renal flare was $38.9 \%$, and it was associated with ESRD. It has been reported that $27 \%-66 \%$ of LN patients experienced at least one renal flare during their follow-up period [48].

In recent years, some studies have brought proteinuria as an important marker for the long-term renal outcome in lupus nephritis [18,49-51]. Interestingly, we found an association of 24-hour proteinuria at baseline, at 6 months, and 12 months with CKD, and a proteinuria at 12 months with ESRD. We also found that serum creatinine and eGFR at baseline, at 6 months, and 12 months were associated with CKD, and both values at LN diagnosis were correlated with ESRD on univariate analysis. Mackay, et al. [51]. published a very recent study proposing risk models to predict future kidney outcomes based on 24-hour proteinuria and serum creatinine at 12 months for use in clinicals trials.

In our study, three factors remained significantly associated with the development of CKD: the time between diagnosis of SLE and diagnosis of LN, hypertension and discontinuation of medications.

Moon, et al. [35] reported that patients with delayedonset LN (defined as newly developed LN after the onset of SLE) progressed more to CKD, than patients with initialonset LN (defined as LN diagnosed at the time of SLE onset) (28\% vs. 16\%; $p=0,004$ ), while Ahn, et al. [52]. reported no difference in renal and overall survival rates between delayed-onset and initial-onset. We demonstrated the opposite: LN diagnosis closer to SLE diagnosis was more associated with the development of CKD. This is worthy of further investigation, but may reflect the severity of nephritis when it is already installed early.

For hypertension, many studies have shown it as a risk factor for CKD [16,17,21,35-39,53]. Presence of hypertension has also been found to be a predictor in Brazilian patients of African extraction [54]. A study using person-year analysis indicated that blood pressure at any time in the clinical course of SLE is a risk factor for deterioration of renal function within 12 or 24 months after the blood pressure measurement [55]. This study proposes that the mean arterial pressure during all follow-up should not exceed $96.5 \mathrm{~mm} \mathrm{Hg}$.

As expected, discontinue treatment for any reason is an important risk factor for CKD, and this should be a warning for patients, doctors and managers, to stimulate the adherence to treatment, to minimize adverse effects, and to create public policies to make the medications ever available.

This study had several limitations. First, all of the data were collected from charts, and detailed information was not available for all variables. Second, the expertise of the various clinicians involved in the management of these patients differed and this would have impacted on the outcome. Third, some critical variables that might impact renal outcomes were not included in our study. In addition, renal biopsies were not performed in all patients and were done at different times of LN. For this reason, we could not analyze the relationship between renal histology and prognosis of nephritis. However, the majority of previous studies have already shown poor renal outcomes in patients with proliferative LN and favorable renal outcomes in patients with class II and V. Despite these limitations, our study is based on a large cohort of a single-center of Northeast of Brazil, and therefore provides representative data about low-income LN patients in Brazilian public tertiary hospital. Additionally, we followed up for a long period of time. Our mean follow-up was 11.2 years, which provided sufficient strength to determine the predictive factors for bad renal outcomes.

\section{Conclusion}

In conclusion, this study showed that CKD and ESRD occurred in $47.2 \%$ and $25.6 \%$ of Brazilian patients with LN, respectively, within 11 years after the diagnosis of LN. Multivariate analysis identified hypertension, discontinuation of medications, and time between diagnosis of SLE and diagnosis of LN as independent variables for the development of CKD.

\section{References}

1. Rovin BH, Stillman I. Chapter 42: Kidney. In: Lahita R, editor. Systemic Lupus Erythematosus. 5th ed. San Diego: Academic Press; 2011. 769-814

2. Hanly JG, O'Keeffe AG, Su L, Urowitz MB, Romero-Diaz J, et al. The frequency and outcome of lupus nephritis: results from an international inception cohort study. Rheumatology (Oxford). 2016; 55: 252-262. PubMed: https://pubmed.ncbi.nlm.nih.gov/26342222/

3. Cervera R, Khamashta MA, Font J, Sebastiani GD, Gil A, et al. European Working Party on Systemic Lupus Erythematosus: morbidity and mortality in systemic lupus erythematosus during a 10year period: a comparison of early and late manifestations in a cohort 
of 1,000 patients. Medicine (Baltimore). 2003; 82: 299-308.

PubMed: https://pubmed.ncbi.nlm.nih.gov/14530779/

4. Font J, Cervera R, Ramos-Casals, García-Carrasco M, Sents J, et al. Clusters of clinical and immunological features in systemic lupus erythematosus: analysis of 600 patients from a single Center. Sem Arthritis Rheum. 2004; 33: 217-230.

PubMed: https://pubmed.ncbi.nlm.nih.gov/14978660/

5. Pons-Estel B, Catoggio L, Cardiel M, Soriano ER, Gentiletti S, et al. The GLADEL multinational Latin American prospective inception cohort of 1,214 patients with systemic lupus erythematosus. Medicine. 2004; 83: 1-17.

PubMed: https://pubmed.ncbi.nlm.nih.gov/14747764/

6. Gasparotto M, Gatto M, Binda V, Doria A, Moroni G, et al. Lupus nephritis: clinical presentations and outcomes in the 21st century. Rheumatology (Oxford) 2020 Dec 5; 59(Suppl5): v39-v51.

PubMed: https://pubmed.ncbi.nlm.nih.gov/33280015/

7. Tsokos GC. Systemic lupus erythematosus. N Engl J Med. 2011; 365: 2110-2121.

PubMed: https://pubmed.ncbi.nlm.nih.gov/22129255/

8. Wang H, Ren Y, Chang J, Gu L, Sun LY. A systematic review and meta-analysis of prevalence of biopsy-proven lupus nephritis. Arch Rheumatol. 2018; 33: 17-25.

PubMed: https://pubmed.ncbi.nlm.nih.gov/29900975/

9. McCullough PA, Verril TA. Cardiorenal interation: appropriate treatment of cardiovascular risk factors to improve outcomes in chronic kidney disease. Postgrad Med. 2010; 122: 25-34

PubMed: https://pubmed.ncbi.nlm.nih.gov/20203453/

10. Stenvinkel P. Chronic kidney disease: a public health priority and harbinger of premature cardiovascular disease. J Intern Med. 2010; 268: 456-467.

PubMed: https://pubmed.ncbi.nIm.nih.gov/20809922/

11. Sule S, Fivush B, Neu A, Furth S. Increased hospitalizations and death in patients with ESRD secondary to lupus. Lupus. 2012; 21: 1208-1203. PubMed: https://www.ncbi.nlm.nih.gov/pmc/articles/PMC4906535/

12. Faurschou M, Starklint H, Halberg $P$, Jacobsen S. Prognostic factors in lupus nephritis: diagnostic and therapeutic delay increases the risk of terminal renal failure. J Rheumatol. 2006; 33: 1563-1569.

PubMed: https://pubmed.ncbi.nlm.nih.gov/16881113/

13. Tan EM, Cohen AS, Fries JF, Masi AT, McShane DJ, et al. The 1982 revised criteria for the classification of systemic lupus erythematosus. Arthritis Rheum. 1982; 25: 1271-1277.

PubMed: https://pubmed.ncbi.nlm.nih.gov/7138600/

14. Weening JJ, D'Agati VD, Schwartz MM. on behalf of the International Society of Nephrology and Renal Pathology Society Working Group on the classification of lupus nephritis. The Classification of Glomerulonephritis in Systemic Lupus Erythematosus Revisited. 2004; 15: 241-250.

15. Levey AS, Eckardt KU, Tsukamoto Y, Levin A, Coresh J, et al. Definition and classification of chronic kidney disease: a position statement from Kidney Disease: Improving Global Outcomes. Kidney Int. 2005; 67: 2089-2100.

PubMed: https://pubmed.ncbi.nlm.nih.gov/15882252/

16. Durahim HA, Ghamdi GA, Seraya AA, Alkhiari R, Sayyari AA. Predictors of mortality and end stage renal disease in Saudi patients with lupus nephritis. Lupus. 2011; 20: 1329-1335.

PubMed: https://pubmed.ncbi.nlm.nih.gov/21813588/

17. Kammoun K, Jarraya F, Bouhamed L, Kharrat M, Makni S, et al. Poor prognostic factors of lupus nephritis. Saudi J Kidney Dis Transpla. 2011; 2: 727-732.

PubMed: https://pubmed.ncbi.nlm.nih.gov/21743218/

18. Yang J, Liang D, Zhang H, Liu Z, Le W, et al. Long-term renal outcomes in a cohort of 1814 Chinese patients with biopsy-proven lupus nephritis. Lupus. 2015; 24: 1468-1478.

PubMed: https://pubmed.ncbi.nlm.nih.gov/26139236/
19. Nossent J, Raymond W, Kang A, Wong D, Ognjenovic M, et al. The current role for clinical and renal histological findings as predictor for outcome in Australian patients with lupus nephritis. Lupus. 2018; 27 : 1838-1846.

PubMed: https://pubmed.ncbi.nlm.nih.gov/30092734/

20. Ayodele OE, Okpechi IG, Swanepoel CR. Predictors of poor renal outcome in patients with biopsy-proven lupus nephritis. Nephrology 2010; 15: 482-490.

PubMed: https://pubmed.ncbi.nlm.nih.gov/20609103/

21. Pakchotanon R, Gladman DD, Su J, Urowitz MB. Sustained complete renal remission is a predictor of reduced mortality, chronic kidney disease and end-stage renal disease in lupus nephritis. Lupus. 2017; 27: 468-474

PubMed: https://pubmed.ncbi.nlm.nih.gov/28857717/

22. Ward MM. Changes in the incidence of end-stage renal disease due to lupus nephritis, 1982-1995. Arch Intern Med. 2000; 160: 3136-3140. PubMed: https://pubmed.ncbi.nlm.nih.gov/11074743/

23. Ward MM. Changes in the incidence of end-stage renal disease due to lupus nephritis in the United States, 1996-2004. J Rheumatol. 2009; 36: 63-67.

PubMed: https://pubmed.ncbi.nlm.nih.gov/19004042/

24. Ishimori ML, Gudsoorkar V, Venturupalli SR, Weisman MH. Disparities in renal replacement in lupus nephritis: current practice and future implications. Arthritis Care Rea. 2011; 63: 1639-1641.

PubMed: https://pubmed.ncbi.nlm.nih.gov/22127964/ +

25. Hiraki L, Lu B, Alexander S, Alarcón GS, Solomon DH, et al. Endstage renal disease due to lupus nephritis among children in the US, 1995-2006. Arthritis Rheum. 2011; 63: 1988-1997. PubMed: https://pubmed.ncbi.nIm.nih.gov/21445963/

26. Ward MM, Studenski S. Systemic lupus erythematosus in men: a multivariate analysis of gender differences in clinical manifestations. J Rheumatol. 1990; 17: 220-224.

PubMed: https://pubmed.ncbi.nlm.nih.gov/2319521/

27. Resende A, Titan S, Barros R, et al. Worse renal outcome of lupus nephritisinmalepatients:acase-controlstudy.Lupus.2011;20:561-567. PubMed: https://pubmed.ncbi.nIm.nih.gov/21415256/

28. Renau Al, Isenberg DA. Male versus female lupus: a comparison of ethnicity, clinical features, serology and outcome over a 30 year period. Lupus. 2012; 21: 1041-1048.

PubMed: https://pubmed.ncbi.nlm.nih.gov/22505605/

29. Urrestarazú A, Otatti G, Silvariño R, Garau M, Coitiño R, et al. Lupus nephritis in males: clinical features, course, and prognostic factors for end-stage renal disease. Kidney Int Rep. 2017; 2: 905-912.

PubMed: https://pubmed.ncbi.nlm.nih.gov/29270496/

30. Fiehn C. Early diagnosis and treatment in lupus nephritis: how we can influence the risk for terminal renal failure. J Rheumatol. 2006; 33: 1464-1466.

PubMed: https://pubmed.ncbi.nlm.nih.gov/16881102/

31. Fiehn C, Hajjar Y, Mueller K, Waldherr R, Ho AD, et al. Improved clinical outcome of lupus nephritis during the past decade: importance of early diagnosis and treatment. Ann Rheum Dis. 2003; 62: 435-439. PubMed: https://pubmed.ncbi.nlm.nih.gov/12695156/

32. Costenbader K, Desai A, Alarcon G, Hiraki LT, Shaykevich T, et al. Trends in the incidence, demographics, and outcomes of end-stage renal disease due to lupus nephritis in the US from 1995 to 2006. Arthritis Rheum. 2011; 63: 1681-1688.

PubMed: https://pubmed.ncbi.nlm.nih.gov/21445962/

33. Ward MM. Access care incidence end-stage renal disease due systemic lupus erythematosus. J Rheumatol. 2010; 37: 1158-1163. PubMed: https://www.ncbi.nlm.nih.gov/pmc/articles/PMC2952403/

34. Maroz N, Segal MS. Lupus nephritis and end-stage kidney disease. Am J Med Sci. 2013; 346: 319-323.

PubMed: https://pubmed.ncbi.nlm.nih.gov/23370533/ 
35. Moon SJ, Kwok SK, Ju JH, Park KS, Park SH, et al. Predictors of chronic kidney disease in Korean patients with lupus nephritis. J Rheumatol. 2011; 38: 2588-2597.

PubMed: https://pubmed.ncbi.nlm.nih.gov/21965650/

36. Sui M, Ye X, Ma J, Yu C, Zhao S, et al. Epidemiology and risk factors for chronic kidney disease in Chinese patients with biopsy-proven lupus nephritis. Intern Med J. 2015; 45: 1167-1172.

PubMed: https://pubmed.ncbi.nlm.nih.gov/26109241/

37. Franco C, Yoo W, Franco D, Xu Z. Predictors of end stage renal disease in African Americans with lupus nephritis. Bull NYU Hosp Jt Dis. 2010; 68: 251-256.

PubMed: https://pubmed.ncbi.nlm.nih.gov/21162701/

38. Vozmediano C, Rivera F, López-Gómez JM, Hernández D. Risk factors for renal failure in patients with lúpus nephritis: data from the Spanish Registry of Glomerulonephritis. Nephron Extra. 2012; 2: 269-277. PubMed: https://pubmed.ncbi.nlm.nih.gov/23139689/

39. Momtaz M, Fayed A, Wadie M, Gamal SM, Ghoniem SA, et al. Retrospective analysis of nephritis response and renal outcome in a cohort of 928 Egyptian lupus nephritis patients: a university hospital experience. Lupus. 2017; 26: 1564-1570.

PubMed: https://pubmed.ncbi.nlm.nih.gov/28625079/

40. Croca SC, Rodrigues T, Isenberg DA. Assessment of a lupus nephritis cohort over a 30-year period. Rheumatology. 2011; 50: 1424-1430. PubMed: https://pubmed.ncbi.nlm.nih.gov/21415024/

41. Uribe AG, Alarcón GS, Sanchez ML, McGwin G, Jr., Sandoval R, et al. Lumina Study Group. Systemic lupus erythematosus in three ethnic groups. XVIII. Factors predictive of poor compliance with study visits. Arthritis Rheum. 2004; 51: 258-263.

PubMed: https://pubmed.ncbi.nlm.nih.gov/15077269/

42. Rivera F, Anaya S. Lupus nephritis flare in young patients: relapse or nonadherence to treatment? Int J Nephrol Dis. 2014; 7: 117-121. PubMed: https://pubmed.ncbi.nlm.nih.gov/24729723/

43. Bertsias GK, Teknidou M, Amoura Z, et al. Joint European League Against Rheumatism and European Renal AssociationEuropean Dialysis and Transplant Association (EULAR/ERA-EDTA) recommendations for the management of adult and pediatric lupus nephritis. Ann Rheum Dis. 2012; 71: 1771-1882.

44. Ichinose $K$, Kitamura $M$, Sato $S$, Eguchi $M$, Okamoto $M$, et al. Complete renal remission at 12 months after induction therapy is associated with renal relapse-free rate in lupus nephritis: a singlecenter, retrospective cohort study. Lupus. 2019; 28: 501-509. PubMed: https://pubmed.ncbi.nlm.nih.gov/30755146/

45. Korbert SM, Lewis EJ, Schwartz MM, Reichlin M, Evans J, et al. for the Lupus Nephritis Collaborating Study Group. Factors predictive of outcome in severe lupus nephritis. Am J Kidney Dis. 2000; 35: 904-914. PubMed: https://pubmed.ncbi.nlm.nih.gov/10793026/

46. Chen YE, Korbet SM, Katz RS, Schwartz MM, Lewis EJ. Collaborative Study Group. Value of a complete or partial remission in severe lupus nephritis. Clin J Am Soc Nephrol. 2008; 3: 46-53.

PubMed: https://pubmed.ncbi.nlm.nih.gov/18003764/

47. Ioannidis JP, Boki KA, Katsorida ME, Drosos AA, Skopouli FN, et al. Remission, relapse, and re-remission of proliferative lupus nephritis treated with cyclophosphamide. Kidney Int. 2000; 57: 258-264. PubMed: https://pubmed.ncbi.nlm.nih.gov/10620207/

48. Sprangers B, Monahan M, Appel GB. Diagnosis and treatment of lupus nephritis flares - an update. Nat Rev Nephrol. 2012; 8: 709-717. PubMed: https://pubmed.ncbi.nlm.nih.gov/23147758/

49. Tamirou F, Lauwerys BR, Dall'Era M, Mackay M, Rovin B, et al. A proteinuria cut-off level of $0.7 \mathrm{~g} /$ day after 12 months of treatment best predicts long-term renal outcome in lupus nephritis. Data from the MAINTAIN Nephritis Trial. Lupus Sci Med. 2015; 2. PubMed: https://pubmed.ncbi.nlm.nih.gov/26629352/

50. Dall'Era m, Cisternas MG, Smilek DE, et al. Predictors of long-term renal outcome in lúpus nephritis Trial: lessons learned from the EuroLupus Nephritis cohort. Arthritis Rheumatol. 2015; 67: 1305-1313.

51. Mackay M, Dall'Era M, Fishbein J, Kalunian K, Lesser M, et al. Establishing Surrogate Kidney End Points for Lupus Nephritis Clinical Trials: Development and Validation of a Novel Approach to Predict Future Kidney Outcomes. Arthritis Rheumatol. 2019; 71: 411-419. PubMed: https://pubmed.ncbi.nlm.nih.gov/30225865/

52. Ahn SS, Yoo J, Jung SM, et al. Comparison of clinical features and outcomes between patients with early and delayed lupus nephritis. BMC Nephrol. 2020; 21: 258.

53. Kostopoulou M, Fanouriakis A, Cheema K, Boletis J, Bertsias G, et al. Management of lupus nephritis: a systematic literature review informing the 2019 update of the joint EULAR and European Renal association-European Dialysis and Transplant Association (EULAR/ ERA-EDTA) reccomendations. RMD Open. 2020; 6: e001263. PubMed: https://pubmed.ncbi.nlm.nih.gov/32699043/

54. de Castro WP, Morales JV, Wagner MB, Graudenz M, Edelweiss MI, et al. Hypertension and Afro-descendent ethnicity: a bad interaction for lupus nephritis treated with cyclophosphamide? Lupus. 2007; 16 : 724-730.

PubMed: https://pubmed.ncbi.nlm.nih.gov/17728366/

55. Ginzler EM, Felson DT, Anthony JM, Anderson JJ. Hypertension increases the risk of renal deterioration in systemic lupus erythematosus. J Rheumatol. 1993; 20: 1694-1700. 